\title{
Sustainability and Science Learning: Perceptions from 8th Grade Students Involved with a Role Playing Activity
}

\author{
Sofia Freire*, Mónica Baptista, Ana Freire \\ Institute of Education, University of Lisbon, Portugal
}

Copyright $\bigcirc 2016$ by authors, all rights reserved. Authors agree that this article remains permanently open access under the terms of the Creative Commons Attribution License 4.0 international License.

\begin{abstract}
Raising awareness about sustainability is an urgent need and as such education for sustainability has gained relevancy for the last decades. It is acknowledged that science education can work as an important context for educating for sustainability. The goal of the present paper is to describe a role-playing activity about the construction of a nuclear power plant and to know how it affected students' perceptions concerning sustainability, their degree of involvement and the type of competencies manifested while involved in the activity. This is qualitative study, adopting an interpretative orientation. Participants were 39 students from 8th grade of elementary education (average age 13 years old). We collected and analyzed students' written documents and focus group interview after the activity was over. Data analysis was inductive. This study shows the importance of bridging science and sustainable education. The role-playing activity made the theme relevant for the students, and they were engaged with searching relevant information, thinking about it, and ways to present and to support their position. By proceeding this way, students became implicated with the theme under discussion and learnt about the curricular topic energy.
\end{abstract}

Keywords Role-playing, Education for Sustainability, Science Education

\section{Introduction}

Nowadays it is fully acknowledged that school is an important context that facilitates the development of relevant competencies as well as students' improved understanding of the complex world they live in [14]. However, paradoxically students show great disinterest with school knowledge, specifically with school science. Many studies centered on students' perspectives highlight the lack of relevance that they attach to the studied themes, its perceived degree of difficulty as well as the traditional nature of science teaching based on knowledge transmission, where students play passive roles [13]. In a different perspective, current society is faced with a multitude of environmental challenges and the urgent need of raising citizens' awareness about sustainability issues. For that, citizens need to acknowledge future generations' needs and recognize the complex interplay of social, economic and environmental systems [19]. Besides, they have to recognize that these challenges concern to the politicians, the scientists, as well as to lay citizens, and to acknowledge that every citizen can develop local actions that may have global consequences. This is even more important as often people are able to identify what is wrong and can point feasible solutions, but do not act given the generalized sense that their single action will not have an impact on the whole; in other situations, citizens do not have well developed competencies that will facilitate their relevant action [11].

Schools can play an important role in changing this state of affairs and particularly school science. Developing science activities that involve issues related to sustainable development, that require from students scientific knowledge and other complex competencies has benefits for learning science, as well as for education for sustainability [3],[20]. The idea of bridging different areas is not new. Many science curricula address this dimension; it is one dimension of the Portuguese science curriculum of elementary education [5]. Besides many authors have been pointing the need to explore the interconnections between science, health and society [6]. However, many studies show that changing teachers' practices and conceptions regarding science education is not easy. Teachers feel pressured to accomplish certain goals, and they hold on to certain views of what should be the goals of science education that inhibit them from developing activities centered on students and from bridging different areas [8]. Considering that developing, testing and disseminating activities might work as an important means to validate new practices and so to facilitate change, this papers' goal is to describe a role-playing activity about the construction of a nuclear power plant. Besides, it aims at knowing how it affected students' perceptions concerning sustainability, as 
well as their degree of involvement and appropriation of the topic under exploration and the type of competencies manifested while involved in the activity.

\section{Education for Sustainability}

Education for sustainability means developing a critical consciousness in people, allowing them to understand and to be alerted to a certain reality, causing them to feel implicated with this reality, and to feel as an integral part of it. This entails the dissemination of values of respect for others, and for diversity, for the environment and for the different resources, but also a posture of constantly seeking solutions that integrate human welfare and economic development, cultural traditions and natural resources [19]. Furthermore, education for sustainability requires knowledge of what sustainable development is, and about the current reality and its challenges, as well as it requires competencies of analysis and of critical thinking. According to Svanstrom [16], it is necessary "the ability to go from local to global considerations, from short-term to long-term, and to realize that the world has been, is and will be changing over time, which changes the conditions for people and different generations" (p. 343). Finally education for sustainability aims at developing more than a critical awareness; it intends to create a willingness to transform and become transformed and a willingness to intervene [9]. This requires reasoning, informed decision making and conscious consideration and evaluation of different hypotheses for action and its consequences, and also a change in attitudes and behaviors. It also requires that individuals recognize themselves as effective change agents [16], as an agent who feels able to do something and who knows what can be made and how.

In order to sensitize students for sustainable development as well as to facilitate the construction of adequate knowledge and competencies, one has to rethink education and curriculum, its purposes and processes. According to Sipos [15], "teaching for sustainability requires transformation to new ways of approaching education and life" (p. 71) and thus it requires a reconstruction of the teaching and learning process. Indeed, education for sustainability does not intend that students learn about sustainability as one more academic content, often requiring from them memorizing and reproducing information passively, in an unengaged way, with no transformation or action. UNESCO [18] mentions that, "Education for Sustainable Development (...) requires participatory teaching and learning methods that motivate and empower learners to change their behavior and take action for sustainable development. Colucci-Gray [4] point to the importance of developing participatory methodologies, namely role-playing activities in facilitating reflection about "the social and environmental aspects of controversial issues but also on the value and the necessity of other people's ideas (i.e. the non-experts, the citizens, people of different cultural extraction ...)" (p.87).

\section{Materials and Methods}

\subsection{Curricular Context}

The activity development took place in 8th grade physics and chemistry classes of a Portuguese public middle school. The students were following the elementary physics and chemistry curriculum, which main goals are 1) to provide students with the ability to raise questions about the natural world, 2) to acquire a general understanding about science ideas and about the explanatory structures of science as well as about its processes and, finally 3 ) to empower students for appraising the relationships between science, technology, society and environment [5]. In order to achieve these goals, the Portuguese elementary science curriculum is organized around the notion of competence and it emphasizes a constructivist approach. The curriculum is organized around four organizing themes, namely Earth in Space; Earth in Transformation; Sustainability of Earth and Better Living on Earth. The role-playing activity was developed within the topic Energy, which is part of the theme Earth in Transformation.

\subsection{Activity's Description}

The activity, related to the construction of a nuclear power plant, lasted two classes of 90 minutes each. It is a role-playing activity starting with a fictitious (but authentic) problem: Suppose that in the city where you live approved the construction of a nuclear power plant. This construction brings enormous benefits, but it also raises many questions that must be addressed. What's your point of view concerning it? In order to answer this question, different groups of students took a specific role (e.g., owner of a nuclear power plant, farmer, member of an association of nature protection, member of the government, Mayor and owner of a thermoelectric power plant) and had to find relevant information for sustaining their position (either agree or disagree with the construction of the nuclear power plant). Each group presented its position and then the whole class discussed the topic using relevant knowledge (For a fuller description, [1]).

\subsection{Participants}

Participants were 39 students of two 8th grade classes (average age 13 years old); 20 were girls and 19 were boys. School was situated in rural setting, and students' interests were mostly related with agricultural issues. In general these students enjoy physics and chemistry classes.

\subsection{Data Collection}

It was a qualitative study, adopting an interpretative 
orientation [7]. An interpretative research provides us with a powerful tool for examining students' meaning construction and thinking. We used different data sources and methods of data collection which is critical for increasing confidence in the results [12]. We collected students written answers to the activity and we carried out focus group interviews after the activity was over. Focus group interviews were very important in order to know what students really learnt, the difficulties they faced and how they dealt with it; it was also essential for exploring students understanding about sustainable development. Five groups of seven to eight students were formed. Groups were homogeneous considering science classes achievement as assessed by the teacher. Interviews were audio-taped and fully transcribed for analysis.

\subsection{Data Analysis}

In order to analyze the data we used categories created based on literature about education for sustainability and also that emerged from the data (Table 1).

Table 1. Categories' description

\begin{tabular}{|c|c|}
\hline Categories & Description \\
\hline $\begin{array}{l}\text { Knowledge } \\
\text { about the topic } \\
\text { under discussion }\end{array}$ & $\begin{array}{l}\text { - Students recognize that some human } \\
\text { actions have complex, interdependent, } \\
\text { political, social, economic and } \\
\text { environmental implications. } \\
\text { Students realize the importance of carefully } \\
\text { thinking and balancing all the implications } \\
\text { in order (1) to protect the future } \\
\text { generations, (2) to preserve of the } \\
\text { environment, and (3) to contribute for a } \\
\text { better living on the planet Earth. }\end{array}$ \\
\hline $\begin{array}{l}\text { Consciousness } \\
\text { about the } \\
\text { importance of } \\
\text { local action }\end{array}$ & $\begin{array}{l}\text { - Students acknowledge that common } \\
\text { citizens can also make relevant contribution } \\
\text { for protecting the future generations, } \\
\text { preserving the environment, and improving } \\
\text { living on the planet Earth. } \\
\text { Students understand the importance of their } \\
\text { local action. }\end{array}$ \\
\hline $\begin{array}{l}\text { Engagement with } \\
\text { local action }\end{array}$ & $\begin{array}{l}\text { - } \quad \text { Students identify a number of actions. } \\
\text { Students express willingness to act and to } \\
\text { change their actions as well as others' } \\
\text { actions. }\end{array}$ \\
\hline $\begin{array}{l}\text { Competencies } \\
\text { for local action }\end{array}$ & 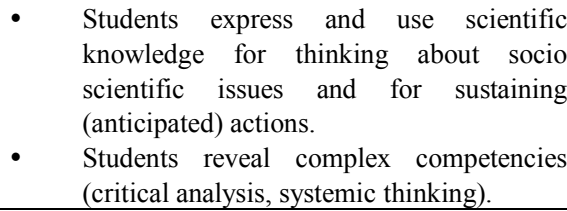 \\
\hline
\end{tabular}

\section{Results}

In general, all working groups as well as interviewed groups were actively involved with the activity and their final products (written works and interview) revealed that they gained knowledge about the implications of constructing a nuclear power plant, they became conscious about the importance of acting locally and to involve others in decision making and finally, that they gained relevant scientific curricular knowledge for supporting their positions.

\subsection{Knowledge about the Topic under Discussion}

Students recognized that the construction of a nuclear power plant is a complex decision, that involves several dimensions and that allows different understandings. For instance, when writing a report about the discussion, one of the groups wrote down,

"There are positive issues that contribute positively for the environment such as spending less oil and coal, and the emission of less polluting gases. However, we cannot forget that there are things that can jeopardize us. Radioactive wastes are a concern and there is the danger of a nuclear accident as well. In this situation, it is not only the local population that becomes affected; this type of accidents has consequences for the entire planet and for future generations. Chernobyl is an example of such an accident. Many people have died from cancer and many children were born with impairments as a consequence of it". (WG4. Written Product).

According to these students, the construction of a nuclear power plant has advantages that will benefit the environment; but simultaneously there is always inherent the danger of a nuclear accident, with negative consequences for the planet and future generations. A similar position is hold by other groups, as illustrated next.

"Currently we want to save oil and to decrease the greenhouse effect. So politicians have to know these issues in order to make a decision concerning a nuclear power plant implementation. We have to consider positive aspects, such as having a rentable energy (...). However, there are also negative issues, such as the problem of nuclear waste and if there is an accident then it will be a planetary catastrophe". (WG8. Written Product).

"We have to consider many arguments in order to make an informed decision and we have to use these arguments. We cannot let construct a nuclear power plant only because it is cost effective; we have to think on the consequences for all the animals, plants, people, environment... everything (...). If there is a problem it can affect the entire planet; we saw the consequences of Chernobyl in the news that we found. But still there are also advantages that are benefic for our planet, decrease of acid rain, decrease of greenhouse effect ..." (IG4. Interview)

Students' answers indicated that they have balanced advantages and disadvantages of a nuclear power plant, and that they considered different points of views. In being involved in this role-playing activity, where they are 
confronted with different points of view held by people occupying different positions (owner of a nuclear power plant, farmer, member of an association of nature protection, member of the government, Mayor and owner of a thermoelectric power plant), they acknowledged the existence of multiple perspectives for exploring this question (social, economic, environmental) which makes the process of decision a complex endeavor. Finally, their answers reflected global thinking - the idea that local actions do impact globally and that current action do impact on future generations.

\subsection{Consciousness about the Importance of Local Action}

Students' answers also revealed that they are aware of the importance of their own local action; and indeed, one important point of students' answers was that they acknowledge that complex decisions has to be participative as they involve issues that affect everyone's lives. Indeed, their answers expressed a sense of responsibility and an understanding of why it is important to develop feasible actions aligned with the new insight. Indeed, students realized that there are things that have to be done, that all citizens have to be involved in decision making, as the environment, the planet and the construction of a better society are issues that belong to all the citizens and not only the politicians. This consciousness is clearly reflected on students following written reports.

"The construction of nuclear power may be important in our town. However, we must ensure that all safety conditions are taken into account, and that we carefully plan the implementation process. (..) However, we also have to consider the disadvantages. It is up to all of us to think about the importance of a nuclear power plant to our city and country and to make ourselves heard". (WG5. Written Product)

"We have to know what the construction of a nuclear power plant involve; we have to know if we are making a good decision, taking in consideration the population well-being, in order to justify our positions and to defend our positions. It was good to have the opportunity to discuss these issues. Now, if there was a project of construction of a nuclear power plant, we would know the problem and the arguments and we would be able to give our opinion. We could even go to the street to raise awareness" (IG3. Interview)

Students in these groups were aware that their actions can have an impact on the decision to implement nuclear power plant, assuming themselves as integral elements of this process. It is important to mention the expressions they used: "It is up to all of us to think about" and "to make ourselves heard.", "to go to the street to raise awareness". They acknowledged that they as citizens can and should participate in informed decisions concerning these issues.
Not only these groups but also other groups frequently used words such as we, our, ours, revealing a high degree of implication and responsibility with the process of decision making [11].

This conscious raise was one dimension positively appraised by these students. Indeed, when they evaluated the activity many comments expressed the insight that now they understand the importance of participating in the process of decision making.

\subsection{Engagement with Local Action}

In addition to recognizing that they as common citizens can do things (and that they should do things in order to protect the future and the planet), students named some actions that they could develop locally, with the aim to influence global decisions (e.g., raise awareness, present their positions and stand up for their positions; sustain their positions). The written documents gave us an account of a number of students' actions if there was an intention to implement a nuclear plant in their city.

"With this activity we learnt how to make a founded decision concerning the construction of a nuclear power plant. It is not only the case of making a decision, but of having adequate knowledge for supporting our decision. Sometimes, people ask things and we cannot correctly answer, as we do not even know what they are talking about or we don't have enough knowledge. But now, if they would want to construct here a nuclear power plant, I would know what to say and I would know how I could make myself heard and even how I could help those people who don't understand the issue under discussion. If I want to help preserving and to improving the place where I live, I have to know how to justify why I consider this action positive or that action negative and I have to think about what is good for people and for the environment". (IG2. Interview)

Students also presented other, very specific and feasible actions. For instance, some students mentioned that they would distribute leaflets.

"We first had to search and to document ourselves about the topic, namely about the vantages and disadvantages of nuclear power plants as well as of other energy sources, so that we could substantiate our ideas and to argument against other positions. (...) Now, if they want to build a nuclear power plant, we can make a slogan and to distribute leaflets in order to inform other persons" (IG1. Interview)

Students were personally involved with the theme, actively thinking and reflecting on the different alternatives, in each other positions and they acknowledged that they can have a word to say. Mention should be made to the verbs: we have, our positions, we would know, we could, 
revealing high willingness to act and to change their actions and the actions of others. One important issue that deserves attention was their notion that in order to participate in decision making, they have to sustain their ideas, and so they have to listen to different positions and to search for accurate information. Indeed, these students pointed as an important action to get informed in order to sustain their ideas and positions, to understand the news in the media and so to understand better what is at stake.

\subsection{Competencies for Local Action}

Besides presenting knowledge about feasible actions, students also revealed new knowledge and other more transversal competencies. For instance, they were able to consider simultaneously different perspectives and to integrate them in a coherent whole; they were able to defend and to argument one position, even when they do not agree with that position (so they were able to take the role of another positions, to understand that positions' arguments and to defend it, and in this context, to dissociate from their own position). As one student explained: "We had to defend a position with which we might even have not agreed with". But as we chose one of the characters, we have to get inside that character and to understand its position. This was very beneficial, as we were able to know much more different positions. This activity made me feel more apt to talk about certain issues". (IG1. Interview)

This was most important as it helped them enlarge their knowledge and also to develop the capacity to decentralize, to take others' roles (as is one of the goals of this type of activity). And finally they had to solve a problem: after considering all the point of views, they had to make a decision and to present a solution to the initial problem: would you build a nuclear power plant? For that they need reasoning competencies, respect by other positions and negotiation, communication but also they have to use problem solving strategies: such as identifying the problem, choosing ways to solve it, dealing with the process and difficulties (inherent in presenting one sole solution for a complex problem that has multiple looks and perspectives). This use of multiple competencies was reflected on several students' written documents, as shown below.

"There are arguments in favor and arguments against the constructing a nuclear power plant that we have to consider in order to make a decision. Arguments against: in Portugal, we can opt for other renewable sources of energy, such as solar energy, Eolic energy; there is still no solution for nuclear waste; this type of energy is expensive; accidents do have severe consequences for living beings and for the entire planet; this type of energy ends up being more polluting if we consider all the life cycle. In favor: the risk of accident is minimal; this type of source does not emit polluting gases that increase the greenhouse effect; fuel has a lower cost; is it a stable energy as it does not depend of climacteric conditions". (WG5. Written Product)

Previous transcription showed adequate scientific knowledge that students were able to use for sustaining a position. They also recognized how important it is to have the right knowledge for gaining confidence and helping them to stand up for their positions.

\section{Conclusions}

The role-playing activity facilitated not only students' learning for sustainability as well as students' construction of knowledge related to the curricular topic Energy. Furthermore, the activity was useful for organizing teaching, as it allowed students to connect science topics to daily experience, making students engage with the activity.

In what concerns students' learning, mention should be made that students realized that there are multiple perspectives involved in the construction of a nuclear power plant (social, economic, environmental), which makes the process of decision a complex endeavor. In addition, they acknowledged that the environment, the planet, and the construction of a better society are issues that belong to all the citizens and not only to the politicians. These understandings seem to be associated with their appreciation of the importance of all citizens (including them) to get involved in decision making. In addition they showed awareness that they can do things (and that they should do things) for protecting the future and the planet, and they actually identified actions that they could develop locally with the aim to influence global decisions. During the class discussion they were able to defend their position, using sustained arguments, even when they did not agree with that position. After considering all the point of views of the group, they made a decision and presented a solution to the initial problem: would you build a nuclear power plant? For that they revealed reasoning and communication competencies and competencies, and they were able to consider simultaneously different perspectives and to integrate them in a coherent whole. All these are important competencies involved in educating for sustainability [9], [17].

In addition, by searching relevant information for sustaining their positions (roles) and exchanging ideas during discussion, students developed new curricular knowledge related to energy, types of energy sources, its advantages and disadvantages, that they were able to use to think about the socio-scientific problem, as expected by the Portuguese elementary science curriculum. And indeed, one important valued dimension were students' notion that in order to participate in decision making, they have to search for relevant information for supporting their ideas.

In what concerns the teaching-learning process, by developing a role-playing activity involving discussion concerning sustainability issues and centered on students, 
teacher made science classes relevant to the students. The role-playing activity worked as an important trigger for initially calling students attention to the theme - the construction of a nuclear power plant and its multiple implications. By interacting with the theme (e.g., exploring it according to different perspectives), the theme became relevant. Mention should be made that in Portugal there are no nuclear power plants. So after gaining knowledge about the complex issues at stake and about the multiple implications involved in the construction of a nuclear power plant, students resized the theme: it was no longer a distant theme (a problem that does not exist in Portugal), but one that may affect globally the entire planet and the future generations. Besides they realized that it is not only a question of environmental implications, but also of social and economic ones. So from a distant theme, the construction of a nuclear power plant became relevant and students became engaged with the activity, searching for more knowledge and information [2], [10], in order to get documented and to be able to support their positions and to argue.

In conclusion, this study shows the importance of bridging science and sustainable education. Furthermore, it supports the advantages of developing teaching practices that start from contexts close to students' reality (or that makes students aware of that proximity). Besides, this study makes a contribution for breaking the traditional tension between teaching with an emphasis on science products or with an emphasis on science processes, as if it was possible to set apart both dimensions of science. Indeed, when students discussed this actual problem that involves complex social, environmental and economic issues, they were required to mobilize scientific knowledge; simultaneously they were deep at the center of the inquiry activity. Indeed another significant dimension of this activity is that students became aware that each position occupied within a social space leads to different points of view. This understanding takes them to the center of the scientific activity. By being involved in processes of questioning, of exploring different perspectives and of building coherent arguments for defending one position, students were able to understand that each point of view is different whether it is based in a different perspective of reality, such as science that looks at reality using different theories, different methods of data collection and so reaches different evidence-based conclusions. Deciding on a valid conclusion involves discussion, argumentation based on scientific evidence, critical analysis of each other's line of reasoning and presented evidences. These were elements of the role-playing activity that focused on issues related with sustainable development and energy sources.

\section{REFERENCES}

[1] Baptista, M., Freire, S. \& Freire, A. (2013). Teaching Science.
Learning for Sustainability. Saarbrücken: LAP LAMBERT Academic Publishing.

[2] Blumenfeld, P.C., Kempler, T.M. \& Krajcik, J.S. (2006). Motivation and cognitive engagement in learning environments. In R.K. Sawyer (ed.), The Cambridge Handbook of the Learning Sciences (pp. 475-488). Cambridge: Cambridge University Press.

[3] Brundiers, K., Wiek, A., \& Redman, C. L. (2010). Real-world learning opportunities in sustainability - from classroom into the real-world. International Journal of Sustainability in Higher Education, 11, 308-324.

[4] Colucci-Gray, L., \& Camino, E. (2011). Environmental crisis and scientific thinking: which science education for sustainability? Journal for Activism in Science \& Technology Education, 3(1), 80-91.

[5] DEB (2001). Currículo Nacional do Ensino Básico. Competências essenciais. Lisboa: Ministério da Educação.

[6] Dillon, J. (2012). Science, Environment and Health Education: Towards a reconceptualisation of their mutual interdependences. In A. Zeyer, \& Kyburz-Graber (eds.), Science, Environment, Health: Towards a renewed pedagogy for science education (pp 87-101). Netherlands: Springer.

[7] Erickson, F. (1986). Qualitative methods in research on teaching. In M. C. Wittroch (Ed.), Handbook of research on teaching. New York, NY: Macmillan.

[8] Galvão, C., Faria, F., Freire, S., Baptista, M. (in press). Curriculum conception, implementation and evaluation: an experience. In B. Akpan (Ed.), Science Education: A Global Perspective. Springer

[9] Jürgensen, A. (2003). Education for sustainability. Developing a sustainable strategy for Zákolany school. Master thesis. The International Institute for Industrial Environmental Economics, Sweden.

[10] Krapp, A. \& Prenzel, M. (2011). Research on Interest in Science: Theories, methods, and findings. International Journal of Science Education, 33(1), 27-50.

[11] Lange, J. M. (2012). Education in sustainable development: How can science education contribute to the vulnerability perception? Research Science Education, 42, 109-127.

[12] Morse (1998). Designing funded qualitative research. In N. Denzin, \& Y. Lincoln (Eds.), Strategies of qualitative inquiry. Thousand Oaks, CA: Sage Publications.

[13] Osborne, J., \& Dillon, J. (2008). Science Education in Europe: Critical Reflections. King's College London: The Nuffield Foundation.

[14] Säljö, R. (2004). From learning lessons to living knowledge. In A-N. Perret-Clermont, C. Pontecorvo, L. Resnick, T. Zittounn \& B. Burge (Eds), Joining society. Social interaction and learning in adolescence and youth (pp. 177-191). Cambridge: Cambridge University Press.

[15] Sipos Y., Battisti, B. \& Grimm, K. (2008) Achieving transformative sustainability learning: engaging heads, hands and heart. International Journal of Sustainability in Higher Education, 9(1), 68-86.

[16] Svanstrom, M. Lozano-Garcia, F. J. \& Rowe, D. (2008). Learning outcomes for sustainable development in higher 
education. International Journal of Sustainability in Higher Education, 9(3), 339-351.

[17] Thomas, I. (2009). Critical Thinking, Transformative Learning, Sustainable Education, and Problem-Based Learning in Universities. Journal of Transformative Education, 7(3) 245-264.

[18] UNESCO (2013). Education for Sustainable Development (ESD). Available on: http://www.unesco.org/new/en/educati on/themes/leading-the-international-agenda/education-for-su stainable-development

[19] UNO (2013). Global sustainable development report. Available on: http://sustainabledevelopment.un.org

[20] Wheeler, K. A. (2000). Introduction. In K. A. Wheeler, \& A. P. Bijur (Eds.), Education for a sustainable future. A paradigm of hope for the 21st century. New York, NY: Kluwer Academic 